\title{
Microarray detection of a de novo der(X)t(X;11)(q28;p13) in a girl with premature ovarian failure and features of Beckwith-Wiedemann syndrome
}

Received: 13 March 2006/ Accepted: 28 March 2006/Published online: 18 May 2006

(C) The Japan Society of Human Genetics and Springer-Verlag 2006

\begin{abstract}
We report an 18-year-old girl with premature ovarian failure (POF), tall stature, and urinary incontinence. Chromosome studies including array comparative genomic hybridization showed that she was the carrier of an unbalanced de novo translocation between the $\mathrm{X}$ chromosome and chromosome 11 , resulting in partial monosomy $\mathrm{Xq}$ and partial trisomy $11 \mathrm{p}$. Microsatellite analysis demonstrated that the patient had paternal duplication of $11 \mathrm{p} 13 \mathrm{p} 15.5$, which contributed to some of her features consistent with Beckwith-Wiedemann syndrome (BWS). The combined phenotype of BWS and POF suggests that the translocated portion of $11 \mathrm{p}$ remains active.
\end{abstract}

Keywords Partial trisomy $11 \mathrm{p} \cdot \mathrm{X}$-autosome translocation · FISH · Microarray ·

Premature ovarian failure

\section{Introduction}

$\mathrm{X}$-autosome translocations are not an infrequent occurrence. In contrast to the generally harmless effects of balanced autosomal translocations, balanced $\mathrm{X}$-autosome translocations very often lead to premature

J.-Y. Han $(\bowtie)$

Department of Laboratory Medicine,

Dong-A University College of Medicine,

1,3-Ga, Tongdaesin-dong, Seo-gu,

Busan, 602-715 Korea

E-mail: jyhan@daunet.donga.ac.kr

Tel: $+82-51-2405323$

Fax: + 82-51-2559366

J.-H. Shin $\cdot$ M.-S. Han · G.-H. Je

Department of Obstetrics and Gynecology,

Dong-A University College of Medicine, Busan, Korea

L.G. Shaffer

Health Research and Education Center,

Signature Genomic Laboratories, LLC,

Washington State University, Spokane, WA, USA ovarian failure (POF), with more than 100 cases reported in post-pubertal women. The majority of individuals with balanced $\mathrm{X}$-autosome translocations exhibit a skewed inactivation of the normal X chromosome. In the case of unbalanced X-autosome translocations, the pattern of inactivation tends to be different, and it is usually the derivative $\mathrm{X}$ chromosome that becomes inactive, if it contains an $\mathrm{X}$ inactivation center. However, the spreading of $\mathrm{X}$ inactivation into the autosomal material may be incomplete and not contiguous. If inactivation does not spread to the autosomal segment, partial trisomy of that segment results in abnormal phenotypes (Sharp et al. 2001, 2002; Hall et al. 2002; Mononen et al. 2003; Yatsenko et al. 2004). Studies of the spreading of $\mathrm{X}$ inactivation into adjacent autosomal segments demonstrate that autosomal DNA may have properties distinct from the $\mathrm{X}$ chromosome that may contribute to resistance against spreading or maintaining $\mathrm{X}$ inactivation.

Here, we describe a case of an $\mathrm{X} ; 11$ translocation in an 18-year-old girl with POF, tall stature, and urinary incontinence. Conventional cytogenetics, fluorescence in situ hybridization (FISH), and molecular genetic studies in conjunction with microarray analysis were performed to characterize the nature of the rearrangement and attempt to correlate the laboratory findings with the clinical phenotype in the patient.

\section{Clinical report}

An 18-year-old girl was referred for evaluation of secondary amenorrhea over the previous 12 months. She had attained menarche at the age of 15 years and always had irregular periods. She is the first child of healthy and non-consanguineous parents. Her younger brother is clinically normal. There was no significant family history. Her birth weight was $4.2 \mathrm{~kg}$ (95 percentile). At age 4 , she was investigated because of mental retardation, macroglossia, and total incontinence. Based on clinical findings, Sotos syndrome was suspected, but further 
tests were not performed. Repeated examination at 10 years of age showed mild hydronephrosis of the left kidney on pelvic ultrasonography, and urinary incontinence persisted after three treatments of collagen injections.

Upon examination at 18 years of age, her height was $177 \mathrm{~cm}$ (97 percentile), and her weight was $68 \mathrm{~kg}$ (97 percentile). She had a long tongue considered macroglossia. Abdominal ultrasound study showed a normal uterus, but the ovaries looked atrophied. Secondary sexual characteristics were delayed, with sparse pubic hair (Tanner stage II) and hypoplastic breasts (Tanner stage II). External genitalia were normal. Plasma follicle-stimulating hormone was $126.2 \mathrm{IU} / 1$, luteinizing hormone was $24.9 \mathrm{IU} / 1$, and estradiol was decreased to less than $5.4 \mathrm{pg} / \mathrm{ml}$. Prolactin, thyroid-stimulating hormone, T3, T4, and free T4 levels were all within normal limits. The patient was advised to take hormone replacement therapy in the near future. The patient was apprehensive and had shy tendencies in social relations. She was suffering from chronic hepatitis B vertically transmitted from the father. Dysmorphic features were not distinct with the exception of tall stature and macroglossia.

\section{Cytogenetic and molecular studies}

Chromosome analysis of peripheral blood lymphocytes by synchronization methods and traditional G-banding showed an abnormal female karyotype with a derivative $\mathrm{X}$ chromosome containing additional genetic material of unknown origin on the long arm (Fig. 1). No other chromosome abnormalities were found. Parental karyotypes were both normal. At this level of resolution, we hypothesized at first a direct duplication of a part of the long arm of $\mathrm{X}$ chromosome. Therefore, FISH was carried out using an $\mathrm{X}$ chromosome-specific painting probe (Vysis, Downers Grove, IL, USA). The distal long arm of the derivative $\mathrm{X}$ chromosome failed to hybridize with the X-specific probe. Subsequent FISH with whole chromosome 13 and 14 paints (Vysis) also did not hybridize to the derivative chromosome (data not shown).

To analyze the origin of the additional genetic materials on the derivative $\mathrm{X}$ chromosome, array comparative genomic hybridization $(\mathrm{CGH})$ analysis was performed using the SignatureChip microarray (Signature Genomic Laboratories, LLC, Spokane, WA, USA). DNA was extracted from fresh peripheral blood. Hybridization, image acquisition, and data analysis were performed as previously described (Bejjani et al. 2005). Microarray analysis demonstrated a single copy loss of DNA at the Xq subtelomeric region and a single copy gain of DNA mapping to the distal short arm of chromosome 11 (Fig. 2). Based on array $\mathrm{CGH}$ results, the additional material was derived from $11 \mathrm{p} 13 \rightarrow 11 \mathrm{pter}$. Thus, combining the results of the G-banded chromosome analysis and microarray experiment, we concluded that the karyotype of the patient is $46, X, \operatorname{der}(\mathrm{X}) \mathrm{t}(\mathrm{X} ; 11)(\mathrm{q} 28 ; \mathrm{p} 13) \mathrm{dn}$, resulting in partial monosomy of distal $\mathrm{Xq}$ and partial trisomy of $11 \mathrm{p}$.

Chromosomal abnormalities that cause duplication of $11 \mathrm{p} 15.5$ often result in Beckwith-Wiedemann syndrome (BWS) when paternally derived and associated with two active copies of the region (Slavotinek et al. 1997). Because the clinical features of this case were thought to be partly caused by the extra copy of distal $11 \mathrm{p}$, we investigated the parental origin of the extra $11 \mathrm{p}$. Microsatellite analysis of tyrosine hydroxylase loci on $11 \mathrm{p} 15.5$ was performed by PCR amplification of DNA from the patient and both parents. Primers were fluorescently labeled to allow quantitation of peak heights following separation on an ABI automated DNA sequencer (Applied Biosystems, Foster City, CA, USA). The patient had one copy of a maternal allele and two copies of one allele present in the father, consistent with a paternal duplication (Fig. 3).

\section{Discussion}

We report the molecular and cytogenetic findings of a patient with an unbalanced $\mathrm{X} ; 11$ translocation resulting in partial monosomy of distal $\mathrm{Xq}$ and partial trisomy of $11 \mathrm{p}$. To our knowledge, there has been only one previous report of unbalanced $\mathrm{X} ; 11$ translocation involving regions similar to those rearranged in our patient (Sharp et al. 2002). In that report, the girl was 5 years old and showed mild developmental delay, large stature (97th percentile), a very long tongue not considered typical macroglossia, and minor facial dysmorphisms. She had a $\operatorname{der}(\mathrm{X}) \mathrm{t}(\mathrm{X} ; 11)(\mathrm{q} 26.2 ; \mathrm{p} 12)$ of paternal origin by PCR analysis, but no further clinicopathological correlations were described. Some of the features found in our subject are consistent with BWS, including mental retardation, large stature, and macroglossia. However, except for macroglossia and tall stature, she did not show other typical clinical features of BWS such as visceromegaly, omphalocele, or ear lobe creases. Sporadic cases of BWS are often caused by a partial paternal disomy of the distal short arm of chromosome 11 (Henry et al. 1991; Bischoff et al. 1995).

In addition to the constellation of clinical features associated with BWS, our patient displayed POF. Results from the investigation of $\mathrm{X}$-autosome balanced translocations and $\mathrm{Xq}$ terminal deletions suggest the presence of two loci on Xq (POF1, located at Xq26-q28; and POF2, located at Xq13.3-q22) that appear to be involved in ovarian function (Marozzi et al. 2000). Microarray analysis for our patient demonstrated a loss of DNA copy number at the $\mathrm{Xq}$ subtelomeric region (Xq28), consistent with the POF1 critical region.

Studies of spreading of $\mathrm{X}$ inactivation into adjacent autosomal segments demonstrate that autosomal DNA has properties distinct from the $\mathrm{X}$ chromosome that might contribute to resistance against spreading or 


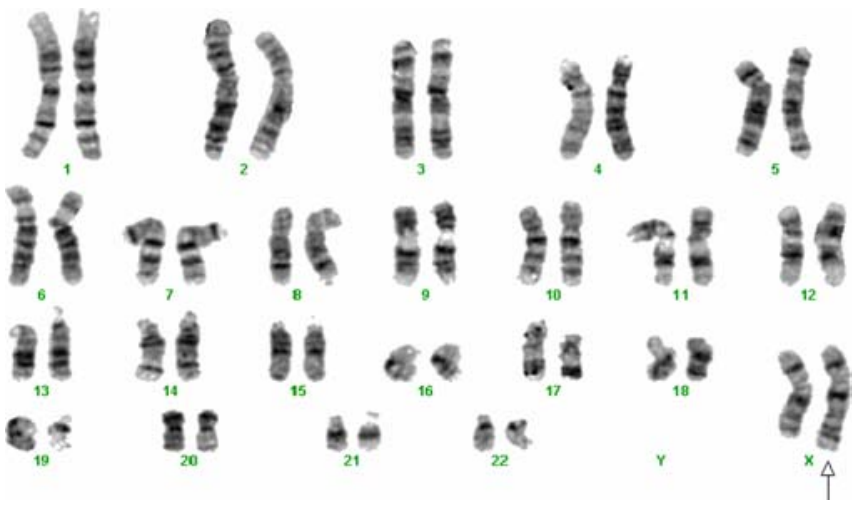

Fig. 1 Karyotype of GTG-banded metaphase chromosomes showing derivative $\mathrm{X}$ with additional genetic materials on its distal long arm (arrow)
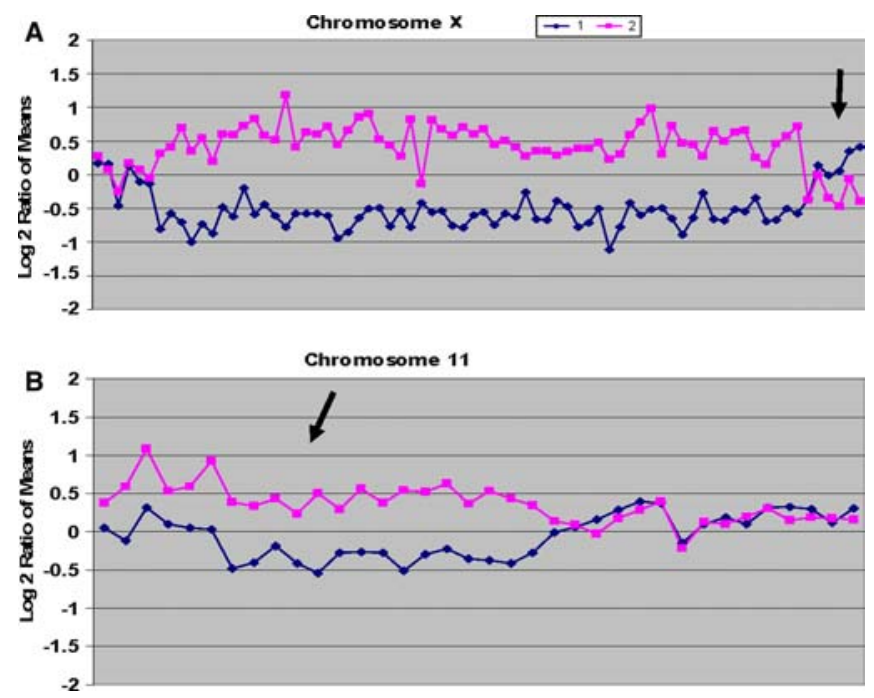

Fig. 2a, b Representative results of microarray data. Each clone on the plot is arranged along the $x$-axis according to its location on the chromosome with the most distal telomeric short arm clones on the left and the most distal/telomeric long-arm clones on the right. The dark blue line represents the control-to-patient fluorescence intensity ratios for each clone, whereas the pink line represents the fluorescence intensity ratios obtained from a second hybridization in which the dyes have been reversed (patient-to-control). a A plot for the $\mathrm{X}$ chromosome. A significant deviation from 0 is expected when a normal female is hybridized against a normal male, because the female has two $\mathrm{X}$ chromosomes whereas the male has one. Thus, the X chromosome looks "duplicated" as compared to the male, showing the pink line above the blue line. However, the pseudoautosomal region in $\mathrm{Xq} 28$ should show a ratio of 0 (normal). However, the plot shows a significant deviation from 0 , demonstrating a deletion of $\mathrm{Xq} 28$ with the blue line above the pink line. b A plot for chromosome 11. The duplication shows a gain (pink above blue) for $11 \mathrm{p} 15.5(\mathrm{p} 13)$

maintaining $\mathrm{X}$ inactivation. Although we have not demonstrated an $\mathrm{X}$ inactivation pattern in the current case, the combined BWS and POF in the patient suggest little or no spreading of inactivation into distal $11 \mathrm{p}$. If some spreading occurred, transcription studies would be necessary to accurately determine the extent of spreading of $\mathrm{X}$ inactivation to the autosomal chromatin.

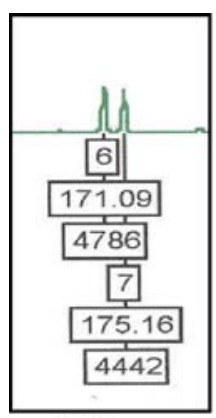

Mother

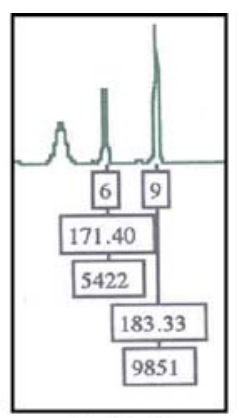

Patient

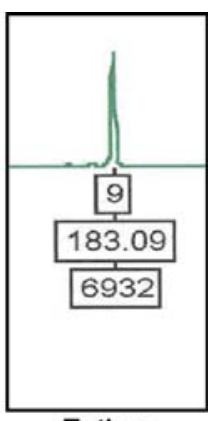

Father
Fig. 3 Allele distribution of patient and both parents for tyrosine hydroxylase loci within the duplicated $11 \mathrm{p}$ region. Allele numbers, peak size, and peak areas are designated in the boxes below each allele peak. The patient had two copies of allele 9 inherited from the father

Acknowledgement This paper was supported by the Dong-A University Research Fund in 2005.

\section{References}

Bejjani BA, Saleki R, Ballif BC, Rorem EA, Sundin K, Theisen A, Kashork CD, Shaffer LG (2005) Use of targeted array-based $\mathrm{CGH}$ for the clinical diagnosis of chromosomal imbalance: is less more? Am J Med Genet A 134:259-267

Bischoff FZ, Feldman GL, McCaskill C, Subramanian S, Hughes MR, Shaffer LG (1995) Single cell analysis demonstrating somatic mosaicism involving $11 \mathrm{p}$ in a patient with paternal isodisomy and Beckwith-Wiedemann syndrome. Hum Mol Genet 4:395-399

Hall LL, Clemson CM, Byron M, Wydner K, Lawrence JB (2002) Unbalanced $\mathrm{X}$; autosome translocations provide evidence for sequence specificity in the association of XIST RNA with chromatin. Hum Mol Genet 11:3157-3165

Henry I, Bonaiti-Pellie C, Chehensse V, Beldjord C, Schwartz C, Utermann G, Junien C (1991) Uniparental paternal disomy in a genetic cancer-predisposing syndrome. Nature 351:665667

Marozzi A, Manfredini E, Tibiletti MG, Furlan D, Villa N, Vegetti W, Crosignani PG, Ginelli E, Meneveri R, Dalpra L (2000) Molecular definition of Xq common-deleted region in patients affected by premature ovarian failure. Hum Genet 107:304-311

Mononen T, Sharp A, Laakso M, Meltoranta RL, Valve-Dietz AK, Heinonen K (2003) Partial trisomy 10q with mild phenotype caused by an unbalanced X;10 translocation. J Med Genet 40:e61

Sharp A, Robinson DO, Jacobs P (2001) Absence of correlation between late-replication and spreading of $X$ inactivation in an X;autosome translocation. Hum Genet 109:295-302

Sharp AJ, Spotswood HT, Robinson DO, Turner BM, Jacobs PA (2002) Molecular and cytogenetic analysis of the spreading of $X$ inactivation in X;autosome translocations. Hum Mol Genet 11:3145-3156

Slavotinek A, Gaunt L, Donnai D (1997) Paternally inherited duplications of $11 \mathrm{p} 15.5$ and Beckwith-Wiedemann syndrome. J Med Genet 34:819-826

Yatsenko SA, Sahoo T, Rosenkranz M, Mendoza-Londono R, Naeem R, Scaglia F (2004) Attenuated phenotype in a child with trisomy for $1 \mathrm{q}$ due to unbalanced $\mathrm{X} ; 1$ translocation [46,X,der(X),t(X;1)(q28;q32.1)]. Am J Med Genet A 128:7277 